\title{
Strategy, IT applications for planning and control, and firm performance: The impact of impediments to IT implementation

\author{
Rong-Ruey Duh ${ }^{\mathrm{a}, *}$, Chee W. Chow ${ }^{\mathrm{b}}$, Hueiling Chen ${ }^{\mathrm{c}}$ \\ ${ }^{a}$ Department of Accounting, National Taiwan University, No. 1, Sec. 4, Roosevelt Road, Taipei, Taiwan, ROC \\ ${ }^{\mathrm{b}}$ School of Accountancy, San Diego State University, California, USA
} \\ ${ }^{\mathrm{c}}$ Department of Finance, National Central University, Taoyuan, Taiwan, ROC
}

Received 29 November 2004; received in revised form 7 March 2006; accepted 22 August 2006

Available online 20 November 2006

\begin{abstract}
Our study examined the association among strategy, the extent of IT applications to 12 planning and control functions, and firm performance. Special attention was paid to the moderating effect on these relationships of 15 technical, human, and organizational impediments to IT implementation. We analyzed survey data obtained from 296 Taiwanese companies, supplemented by financial data from publicly disclosed financial reports. Results indicated that strategy significantly influenced the extent of IT applications for planning and control. In turn, the extent of IT applications had a significant direct effect on firm performance, while the direct effect of strategy was insignificant. The relationship between strategy and the extent of IT applications, and between the latter and firm performance were both stronger when the level of impediments to IT implementation was low. The findings went beyond these general relationships to reveal systematic differences in the specific IT applications and impediments of firms pursuing different strategies.
\end{abstract}

(C) 2006 Elsevier B.V. All rights reserved.

Keywords: Strategy; Information technology (IT) applications; Performance; Impediments to IT implementation

\section{Introduction}

Advances in IT have vastly increased firms' ability to collect, analyze, and disseminate information. In this regard, it is commonly held that the benefits from IT applications depend on the extent to which they are congruent with the firm's objectives and strategy $[7,38,44]$. Yet extant studies on the relationship among strategy, IT and performance (e.g., [14]) have only considered IT investment or infrastructure as a whole without examining the specific uses to which IT is put. As

\footnotetext{
* Corresponding author. Tel.: +88623366 3888; fax: +886223637440.

E-mail address: rrduh@ntu.edu.tw (R.-R. Duh).
}

such, the findings have limited our ability to guide firms' selection of IT applications. On the other hand, while accounting research has investigated the associations among strategy, specific features of accounting IS and performance (e.g., [24]), it has not considered the role of IT in IS design. In view of this gap, we explored how a number of specific IT applications in planning and control interact with strategy to affect firm performance.

In undertaking our investigation, we included four different approaches:

1. Rather than treating them as whole, we considered the IT components as 12 separate applications.

2. As many systems fail to produce their intended result, we considered factors that may impede their implementation. Indeed, a survey conducted by the 
Gartner Group indicated that about $40 \%$ of IT projects failed and that, on average, companies spent US\$ 1 million a year on unsuccessful projects, on top of wasted professional resources that could not be easily quantified [2]. We therefore investigated how 15 specific impediments affected the relationship between strategy and the extent of IT applications, as well as that between the extent of IT applications and performance.

3. Because past studies of the relationship between IT investment and firm performance have yielded mixed results (e.g., [13,15,18,27,37,49]), we attempted to examine both objective and subjective measures of performance. We included both financial and nonfinancial measures, incorporating some leading indicators, some being lagging measures of performance.

4. With the exception of Jenster [32], past studies investigating the strategy-IT-performance relationship used the same criteria to compare the performance of firms with different strategies. But firms do not emphasize the same outcomes [6]. In particular, a firm's strategic mission signifies its intended trade-offs between future growth and shortterm earnings/cash flow maximization [1]. Thus using the same performance measures to compare firms with different strategies has biased the results. We therefore developed different sets of performance measures to fit different strategies. The set was validated by experienced managers prior to its use.

Since most of the needed data are not publicly available, a survey was used as the primary means for collecting them from a large random sample of publicly held Taiwanese companies. The results were based on responses from 296 end users of IT applications, CFOs; they showed that strategy significantly influenced the extent of IT applications for planning and control. Further, there was a statistically significant positive relation between the extensiveness of IT applications and organizational performance. Both sets of relationships were moderated by the level of impediments to IT implementation, thus underlining the need to anticipate and overcome obstacles to effective IT deployment.

\section{Prior literature and research hypotheses}

\subsection{Association among strategy, the extent of IT applications for planning and control, and firm performance}

A number of studies have made the point that IT has strategic implications and that its design has to be aligned with the firm's competitive needs. Floyd and Wooldridge [20] used data from 127 banks and interviews with 68 bank CEOs to examine the relationship among competitive strategy, information technology, and organizational performance. They found that competitive strategy significantly affected IT adoption. Further, product IT significantly affected firm financial performance, whereas the effect of process IT was insignificant. $\mathrm{Li}$ and Ye [40] investigated the moderating effects of environmental dynamism, firm strategy, and nature of the CEO/CIO arrangement on the relation between IT investment and firm performance. They found that IT investment had a stronger positive impact on financial performance when there were greater environmental changes, more proactive company strategies, and closer $\mathrm{CEO} /$ CIO ties.

Researchers in the strategic management literature also underscored the impact of corporate strategy on IT design. Galbraith [21] argued that, as organizations face increased complexity and uncertainty, they require more information for decision-making. And since managers have limited cognitive capability for processing information, increasing organizational information processing capacity via IT is the only way to cope with increased complexity and uncertainty without reducing performance. Brandyberry et al. [8] also suggested that IT had the potential to manage the information flow and to impact many dimensions of the supply chain and ultimately the profits of the firm.

More specifically, Miles and Snow [42] delineated different information needs and system requirements across business strategies. Govindarajan and Shank [25] argued that firms following a build strategy (focused on increasing market share) were confronted with greater needs to cope with environmental complexity and uncertainty than were firms following a harvest strategy of increasing short-term cash flows. Along the same vein, Gordon and Miller [22] suggested that firms following a build strategy had greater demands for information timeliness, accuracy, integrative complexity, and responsiveness.

On the whole, the literature provided a strong basis for expecting that the extent of IT application for planning and control would differ for firms adopting different strategies, in turn affecting firm performance. These general expectations are summarized in our first two hypotheses.

Hypothesis 1. The extent of IT applications for planning and control differs across firms with different strategies. 
Hypothesis 2. The extent of IT applications for planning and control is positively associated with firm performance.

\subsection{Impediments to IT implementation}

According to a survey by Umble and Umble [47], the primary cause of IT project failure is inadequate attention to human and organizational factors. If a firm's IT applications are tied to its strategy, they are likely to affect most of the business functions. When people's job content, spheres of influence and routines are affected, they are prone to resist the change [33], and Dos Santos and Sussman [19] noted that a major impediment to deploying IT strategically was senior management's failure to overcome resistance to change. In a study of MRP applications, Cooper and Zmud [17] concluded that organizational resistance and lack of MRP understanding inhibited MRP infusion more than the task fit of MRP. Relating to ERP systems, Umble and Umble also suggested that implementation failures fall into eight categories, most of which are related to human and organizational, rather than technology-related, factors (e.g., poor leadership, inadequate education and training, trying to maintain the status quo, and staff resistance).

Together, these studies suggested that a firm's ability to link its IT applications to strategy would vary inversely with the strength of the impediments to IT implementation. Similarly, such impediments also adversely affect the firm's ability to reap the performance benefits of IT applications:

Hypothesis 3. The link between a firm's strategy and its extent of IT applications for planning and control varies inversely with the level of impediments to IT implementation.

Hypothesis 4. The link between a firm's extent of IT applications for planning and control and performance varies inversely with the level of impediments to IT implementation.

\section{Method}

\subsection{Overview}

Two factors motivated our use of a survey as the primary means of data collection. First was that much of the data needed was neither quantified nor publicly available. Second was our desire for a large sample.

The survey (as shown in Appendix A) included questions on strategy, the types of IS software in use, the extent of IT applications for 12 planning and control functions, the presence of 15 specific impediments to IT implementation, firm performance, and demographics. These questions were first developed by referencing previous studies $[23,26,30,39,48,50]$, and then modified based on feedback from interviews with 19 senior accounting and finance managers of five Taiwanese companies not in the sample.

\subsection{Sample}

We sought a sample of 300 usable responses so that there would be adequate data density across strategies, IT applications, and impediments. An examination of prior survey research published in three major management journals in Taiwan showed that, on average, IT-related surveys had a response rate of about $25 \%$. Hence, we randomly selected 1200 companies out of the 2350 publicly held firms in 2002. The CFO of each company was sent a copy of the questionnaire along with a cover letter explaining the objective of the study. Each survey had an identification number so that external financial data could be linked to the survey responses. The cover letter assured CFO that this number would not be used to identify any respondent or firm in reporting the results. A pre-addressed and stamped envelope also was enclosed. A total of 301 (25.1\%) completed surveys were returned, of which 296 were usable.

The demographic data showed that our sample came from a wide range of industries, with electronics being the largest subset (35.2\%). In terms of number of employees, $10 \%$ of the sample firms had 1-100 employees, $57 \%$ had 101-500 employees, and 33\% had over 500 people. About $82 \%$ of the firms had significantly or noticeably computerized their operations.

On average, the respondents were 41 years old and had held their present positions for 4.5 years. They had been working full time at their companies for 7.6 years on average, and reported spending an average of $3.5 \mathrm{~h}$ per day on the Internet. Thus, the respondents were sufficiently experienced and informed for participation in our study.

\subsection{Measures}

\subsubsection{Strategy}

Respondents were asked to select from four descriptions the one that best described their firms' competitive strategy. We adopted the build, hold, harvest, and divest taxonomy because these descriptions are well documented in and representative of the strategy literature $[3,28]$, and because they had been extensively tested in prior studies. 
The survey results showed a distribution of 186 "build" companies (62.8\%), 74 "hold" companies (25\%), and 36 "harvest" companies (12.2\%). No respondent indicated that his company followed a "divest" strategy. As a validity check, we compared perceived environmental uncertainty across firms with different strategies. Our premise, based on the prior research was that firms following a build strategy should be faced with relatively higher environmental uncertainty. This expectation was supported by the ANOVA results. Perceived environmental uncertainty varied with the type of strategic mission $(F=219, p=0.000)$, and firms with a build strategy perceived higher environmental uncertainty than those with other strategic missions (i.e., hold or harvest, $p=0.000$ ).

\subsubsection{The extent of IT applications for planning and control}

Respondents were asked to indicate whether their company used the IS for each of 12 planning and control functions (yes $=1$, no $=0$ ). These 12 items were based on Comshare [16], and spanned decision support, budgeting, and performance measurement. Components of the decision support function included variance analysis/management reporting, product costing/expense analysis, sales performance reporting/analysis, customer/channel profitability reporting/ analysis, manufacturing/inventory analysis, and sales/ channel variance analysis. Budgeting items include department budgeting, capital budgeting, and sales forecasting. Finally, items relating to performance measurement included financial consolidations/ reporting, measuring key performance indicators, and measuring/reporting business unit profitability. Since there was no a priori reason for ascribing different degrees of importance to the 12 functions, we used the total number of applied functions to measure the extent of IT applications for planning and control. The Cronbach $\alpha$ for the 12-item scale was 0.725 .

\subsubsection{Impediments to IT implementation}

Respondents were asked to indicate the extent to which each of the 15 impediments had been seen to be present in their company's IT implementation $(1=$ "not at all" and $5=$ "to a very great extent"). This list of impediments was derived from the literature. The Cronbach $\alpha$ for the 15 items was 0.890 .

\subsubsection{Firm performance}

Extant studies on IT investment and performance mainly focused on financial performance, such as cost reduction, profitability (e.g., return on assets, return on sales, return on equity, or profit margin), efficiency (e.g., fixed assets or inventory turnover), or stock price/ returns (e.g., [12,45,46]). Other studies have measured market share gain, market penetration, quality improvement, and productivity (e.g., [11]). On the whole, findings on the relationship between IT investment and performance have been inconclusive, giving rise to the so-called "productivity paradox" $[10,41]$.

Critics of this effort suggest that the equivocal findings may be ascribed to shortcomings of the measures used to gauge performance [9]. It is argued that over-reliance on financial measures places too much emphasis on maximization of stockholders' wealth without considering the impacts on other stakeholders [34]. Financial performance measures are also criticized for being too aggregated, short-term focused and backward looking (e.g., [31]).

To overcome these limitations, we adopted the approach of balanced scorecard advocates (e.g., [35]) by including multiple aspects of performance, and operationalizing these with financial and non-financial measures that encompass both leading and lagging indicators. All of the 19 high-level managers who we interviewed in developing the instrument affirmed that seven measures were both an appropriate and reasonably complete set of measures at the firm level:

Financial performance:

(1) long-run profitability;

(2) growth rate of revenues;

(3) financial strength.

Customer-related performance:

(4) public image and goodwill.

Internal process performance:

(5) innovativeness;

(6) continuous improvement.

Learning and growth performance:

(7) employee morale, job satisfaction and commitment.

Respondents were asked to rate their companies' performance on each of these seven dimensions relative to the industry average, so as to control for the effects of industry and other common external factors. The 7point Likert scale was anchored on $1=$ "very low," $4=$ "about average" and $7=$ "very high".

Consistent with our earlier argument that firms following different strategies should be evaluated with different performance measures, we compiled different subsets of the seven measures for the three strategy types. The following subsets were first developed 
based on the literature, then minor modifications were made after discussions with the 19 high-level managers:

- Build: long-run profitability; growth rate of revenues; financial strength; public image and goodwill; employee morale, job satisfaction and commitment; innovativeness.

- Hold: employee morale, job satisfaction, and commitment; public image and goodwill; continuous improvement.

- Harvest: employee morale, job satisfaction and commitment; public image and goodwill; financial strength.

Since our analysis involved comparing performance across firms with different strategies, it was necessary to control for differences in the total number and specific nature of performance elements. Thus, we standardized (i.e., we converted into a distribution with zero mean and unit variance) the aggregate performance measures for each strategy type. We found that standardized performance was not significantly correlated with strategic mission $(r=0.033, p=0.571)$, indicating that variations in performance were mainly due to factors other than the strategic mission.

\section{Results}

\subsection{Preliminary analysis}

\subsubsection{Testing for non-response bias}

Although the 296 usable responses represented a rather favorable $24.7 \%$ response rate, it was desirable to further dispel concern about non-response bias. To do this, we compared strategy, the extent of IT applications, and impediments to IT implementation between the 60 earliest and latest responses. None of these comparisons produced significant $t$-values at the $p=0.05$ level. This provided some assurance that non-response bias was not present in our study $[4,36]$.

\subsubsection{The extent of IT applications for planning and control}

Table 1, in Panel A, shows that the sample firms use a wide variety of software systems, with almost half being developed in-house. Panel B shows that there also is divergence in the areas of IT application. At the high end of the spectrum, 249 firms (84.1\%) reported applications for product costing/expense analysis, 241 firms $(81.4 \%)$ reported applications in department budgeting, $230(77.7 \%)$ reported using IT to perform variance analysis/management reporting, and 185 (62.5\%) indicated applications in sales performance reporting/

Table 1

Use of information system software

\begin{tabular}{|c|c|c|}
\hline Name of information system software & Number of respondents & Percentage \\
\hline \multicolumn{3}{|l|}{ Panel A: type of software in use } \\
\hline Oracle financials & 38 & 12.8 \\
\hline SAP & 33 & 11.1 \\
\hline J.D. Edwards & 8 & 2.7 \\
\hline Peoplesoft & 2 & 0.7 \\
\hline In-house/proprietary system & 132 & 44.6 \\
\hline Other & 83 & 28.1 \\
\hline Total & 296 & \\
\hline Functions to which IT is applied & Number of respondents & Percentage \\
\hline \multicolumn{3}{|l|}{ Panel B: IT applications in planning and control } \\
\hline Product costing/expense analysis & 249 & 84.1 \\
\hline Departmental budgeting & 241 & 81.4 \\
\hline Variance analysis/management reporting & 230 & 77.7 \\
\hline Sales performance reporting/analysis & 185 & 62.5 \\
\hline Manufacturing/inventory analysis & 180 & 60.8 \\
\hline Financial consolidation/reporting & 175 & 59.1 \\
\hline Measuring/reporting business unit profitability & 160 & 54.1 \\
\hline Sales forecasting & 155 & 52.4 \\
\hline Customer/channel profitability reporting/analysis & 149 & 50.3 \\
\hline Measuring key performance indicators & 135 & 45.6 \\
\hline Capital budgeting & 111 & 37.5 \\
\hline Sales/channel variance analysis & 108 & 36.5 \\
\hline
\end{tabular}


Table 2

Summary of direct and indirect effects from the path model (tests of H1 and H2)

\begin{tabular}{|c|c|c|c|c|}
\hline Dependent variable & Independent variable & Direct effect & Indirect effect & Total effect \\
\hline The extent of IT applications & Strategy & $0.278^{* * * *}$ & & 0.278 \\
\hline \multirow[t]{2}{*}{ Performance } & The extent of IT applications & $0.576^{* * *}$ & & 0.576 \\
\hline & Strategy & 0.008 & 0.005 & 0.013 \\
\hline
\end{tabular}

Self-reported (standardized) performance measures are used in the path model.

**** $p<0.01$ (two-tailed).

analysis. At the low end of the spectrum, only $36.5 \%$ of the firms (108) reported using IT for sales/channel variance analysis.

\subsubsection{Impediments to IT implementation}

Among the 15 impediments, respondents identified four as being particularly prevalent: software that failed to meet the business' demand, lack of system flexibility, lack of integration with existing systems, and lack of prior planning (means $=3.28,3.27,3.12$, and 3.09, respectively on a $1-5$ scale). In comparison, insufficient top management support, employees' resistance to change, and insufficient people were seen as being less severe obstacles (means $=2.54,2.30$, and 2.53, respectively).

\subsection{Hypotheses tests}

\subsubsection{The association among strategy, the extent of} application of IT for planning and control, and firm performance

Table 2 presents the direct and indirect effects of a path model for testing $\mathrm{H} 1$ and H2. Strategy had a significant and direct impact on the extent of IT applications for planning and control $(p=0.000)$. Thus, $\mathrm{H} 1$ was supported. $\mathrm{H} 2$ also was supported, as the extent of IT applications had a significant and direct impact on performance $(p=0.000)$.

Table 3 provides more details on the nature of IT applications by firms following different strategies. Overall, firms following a build strategy applied IT most extensively, followed by hold and harvest firms, in that order (mean numbers of applications $=7.49,6.33$, and 5.31, respectively, out of 12). Table 3 also shows that IT was applied to each decision support function by more than half of the companies following a build strategy. And while firms of all three strategy types extensively applied IT to decision support functions like variance analysis/management reporting and product costing/expense analysis, those with a build strategy particularly emphasized applications to customer/ channel profitability reporting/analysis and sales/channel variance analysis. This probably was because build companies have a greater need for information to explore and develop potential market segments and to

Table 3

The distribution of IT applications across firms with different strategies

\begin{tabular}{|c|c|c|c|}
\hline & \multicolumn{3}{|l|}{ Type of strategy } \\
\hline & Build $(N=186)$ & Hold $(N=74)$ & Harvest $(N=36)$ \\
\hline \multicolumn{4}{|l|}{ Decision support } \\
\hline Product costing/expense analysis & $159(85.5 \%)$ & $63(85.1 \%)$ & $27(75.0 \%)$ \\
\hline Variance analysis/management reporting & $148(79.6 \%)$ & $59(79.7 \%)$ & $23(63.9 \%)$ \\
\hline Sales performance reporting/analysis & $125(67.2 \%)$ & $40(54.1 \%)$ & $20(55.6 \%)$ \\
\hline Manufacturing/inventory analysis & $125(67.2 \%)$ & $36(48.6 \%)$ & $19(52.8 \%)$ \\
\hline Customer/channel profitability reporting/analysis & $106(57.0 \%)$ & $38(51.4 \%)$ & $5(13.8 \%)$ \\
\hline Sales/channel variance analysis & $95(51.1 \%)$ & $12(16.2 \%)$ & $1(2.7 \%)$ \\
\hline \multicolumn{4}{|l|}{ Budgeting } \\
\hline Department budgeting & $153(82.3 \%)$ & $60(81.1 \%)$ & $28(77.8 \%)$ \\
\hline Sales forecasting & $111(59.7 \%)$ & $30(40.5 \%)$ & $14(38.9 \%)$ \\
\hline Capital budgeting & $72(38.7 \%)$ & $36(48.6 \%)$ & $3(8.3 \%)$ \\
\hline \multicolumn{4}{|l|}{ Performance measurement } \\
\hline Measuring/reporting business unit profitability & $102(54.8 \%)$ & $43(58.1 \%)$ & $15(41.7 \%)$ \\
\hline Financial consolidation/reporting & $87(46.8 \%)$ & $70(94.6 \%)$ & $18(50.0 \%)$ \\
\hline Measuring key performance indicators & $87(46.8 \%)$ & $40(54.1 \%)$ & $8(22.2 \%)$ \\
\hline Mean number of applications & 7.49 & 6.33 & 5.31 \\
\hline
\end{tabular}

Boldface is used to highlight those functions with IT applications by more than $50 \%$ of the firms following a given strategy. 
build market share early in the growth phase of products or services.

Focusing on the budgeting function, more than $75 \%$ of the sample firms applied IT to department budgeting, indicating the general usefulness of IT to this function regardless of strategy. In contrast, only firms following a build strategy emphasized IT application to sales forecasting, while firms following a hold strategy applied IT to capital budgeting more extensively than build and harvest firms $(48.6 \%, 38.7 \%$, and $8.3 \%$, respectively). Finally, relative to firms pursuing build and harvest strategies, firms following a hold strategy used IT more extensively in financial consolidation/reporting and for measuring key performance indicators.

\subsubsection{The moderating effects of impediments to IT implementation}

We had hypothesized that impediments to IT implementation moderated both the link between strategy and the extent of IT applications for planning and control (H3), and the link between the extent of IT applications and firm performance (H4). To test the efficacy of the first prediction, we used the following moderated regression:

$Y_{1}=a_{1}+a_{2} X_{1}+a_{3} X_{2}+a_{4} X_{1} X_{2}+\mathrm{e}_{1}$

where $Y_{1}$ denotes the extent of IT applications; $X_{1}$ represents strategy with $1=$ harvest, $2=$ hold, and 3 = build; $X_{2}$ is the extent of impediments to IT implementation.

To test H4, we used the following moderated regression:

$Y_{2}=b_{1}+b_{2} X_{2}+b_{3} X_{3}+b_{4} X_{2} X_{3}+\mathrm{e}_{2}$

where $Y_{2}$ denotes (standardized) firm performance; $X_{3}$ represents the extent of IT applications.
Consistent with $\mathrm{H} 3$, the interaction of strategy and impediments to IT implementation had a negative and significant effect on the extent of IT applications $(t=-3.635, p=0.000)$, implying that the effect of strategy on the extent of IT applications decreased as impediments to IT implementation increased. And consistent with $\mathrm{H} 4$, the extent of IT applications and impediments to IT implementation had a negative and significant interactive effect on firm performance $(t=-3.905, p=0.000)$.

To gain additional insight into the impediments' moderating effects, we used the median to split the sample into low and high impediment halves (means of the two halves are 2.26 and 3.51, respectively; $t=23.0$; $p=0.000)$. Then we recalculated the path coefficients. Panels A and B of Table 4 present the results for the strategy-application and application-performance links, respectively.

Consistent with $\mathrm{H} 3$, the path coefficient between strategy and the extent of IT applications was statistically significant at the low $(p=0.000)$, but not the high $(p=0.142)$ level of impediments to IT implementation. Thus, firms that were faced with higher impediments had less extensive use of IT for planning and control, as compared to those pursuing the same competitive strategy. Support also was obtained for H4. The path coefficient between the extent of IT applications and performance was positive and significant for the firms facing a low level of impediments to IT implementation $(p<0.000)$, but insignificant for firms facing a high-level of impediments $(p=0.129)$.

As an alternative test, we used median values to divide our sample into four applications-performance subgroups: high-high, high-low, low-high, and lowlow. Table 5 shows the extent of each impediment for each subgroup as well as the overall means.

An inspection reveals some interesting features. The lowest impediment is the same across all four

Table 4

Summary of direct and indirect effects from the path model (tests of H3 and H4)

\begin{tabular}{|c|c|c|c|c|}
\hline Dependent variable & Independent variable & Direct effect & Indirect effect & Total effect \\
\hline \multicolumn{5}{|c|}{ Panel A: firms with low impediments to IT implementation } \\
\hline The extent of IT applications & Strategy & $0.443^{* * *}$ & & 0.443 \\
\hline \multirow{2}{*}{ Performance } & The extent of IT applications & $0.584^{* * *}$ & & 0.584 \\
\hline & Strategy & 0.013 & 0.259 & 0.272 \\
\hline \multicolumn{5}{|c|}{ Panel B: firms with high impediments to IT implementation } \\
\hline The extent of IT applications & Strategy & 0.121 & & 0.121 \\
\hline \multirow[t]{2}{*}{ Performance } & The extent of IT applications & 0.126 & & 0.126 \\
\hline & Strategy & 0.002 & 0.015 & 0.017 \\
\hline
\end{tabular}

Self-reported (standardized) performance measures are used in the path model.

**** $p<0.01$ (two-tailed). 
The average extent of impediments to IT implementation

\begin{tabular}{|c|c|c|c|c|}
\hline & \multicolumn{2}{|c|}{ Firms with high IT applications } & \multicolumn{2}{|c|}{ Firms with low IT applications } \\
\hline & $\begin{array}{l}\text { High firm } \\
\text { performance }\end{array}$ & $\begin{array}{l}\text { Low firm } \\
\text { performance }\end{array}$ & $\begin{array}{l}\text { High firm } \\
\text { performance }\end{array}$ & $\begin{array}{l}\text { Low firm } \\
\text { performance }\end{array}$ \\
\hline Lack of system flexibility & 2.56 & 2.73 & 3.48 & 3.80 \\
\hline System cost too high & 2.51 & 2.59 & 3.07 & 3.47 \\
\hline Insufficient time & 2.49 & 2.53 & 2.97 & 3.35 \\
\hline Software function cannot meet the business' demand & 2.42 & 2.94 & 3.57 & 3.71 \\
\hline Difficult to consolidate data & 2.42 & 2.63 & 3.32 & 3.35 \\
\hline Lack of planning beforehand & 2.33 & 2.77 & 3.38 & 3.47 \\
\hline Lack of quality staff & 2.33 & 2.61 & 3.01 & 3.20 \\
\hline Insufficient integration with existing systems & 2.31 & 2.63 & 3.36 & 3.65 \\
\hline Inadequate training & 2.27 & 2.69 & 3.02 & 3.59 \\
\hline Insufficient resource (beyond people and time) & 2.27 & 2.44 & 2.75 & 3.16 \\
\hline Lack of system stability & 2.20 & 2.48 & 3.16 & 3.24 \\
\hline Insufficient people & 2.02 & 2.02 & 2.69 & 2.97 \\
\hline Lack of specification of objectives & 1.96 & 2.19 & 2.92 & 3.13 \\
\hline Insufficient top management support & 1.80 & 2.13 & 2.60 & 3.16 \\
\hline Employees' resistance to change & 1.76 & 1.98 & 2.35 & 2.77 \\
\hline Overall mean & 2.24 & 2.49 & 3.04 & 3.33 \\
\hline
\end{tabular}

subgroups: "employees' resistance to change" $($ means $=1.76,1.98,2.35$, and 2.77). At the other end of the spectrum, the highest impediment to both high (applications)-high (performance) and low-low firms was "lack of system flexibility" (means $=2.56$ and 3.80 ), while the highest impediment to the high-low and low-high firms was "software function cannot meet the business' demand".

Comparing columns 1 and 2, all impediments were lower for firms with high IT applications and high performance than for high IT application firms with low performance (means $=2.24$ and 2.49, $t=-2.221$, $p=0.028)$. The same difference was observed among high and low performers with low levels of IT applications (columns 3 and 4) (means $=3.04$ and 3.33, $t=-2.812, p=0.006)$. As a whole, these additional tests further confirmed the negative moderating effect of impediments on the relationship between IT applications and firm performance.

\subsubsection{Robustness tests using objective performance measures}

Since subjective performance assessments were open to potential biases (e.g., judgment, leniency) [43], we buttressed our performance tests with measures derived from the sample firms' publicly disclosed financial reports (i.e., objective performance measures). We measured long-run profitability with 3-year average profit growth, and proxied growth rate of revenues with 3 -year average sales growth. Return on assets, the current ratio, and the debt-to-equity ratio were used to measure financial strength, and R\&D expense scaled by sales was used to measure the extent of innovativeness [5,29]. Employee turnover was used to gauge employee morale, job satisfaction, and commitment. We also used sales returns scaled by sales to measure public image and goodwill, although this proxy is admittedly crude. Data for computing these objective measures were obtained from the Taiwan Economic Journal database, which is compiled from the publicly disclosed financial statements of firms listed on the Taiwan Stock Exchange. Two hundred and sixty of our sample firms were included in this database. Replicating the moderated regression analyzes and path models with the standardized objective performance measures yielded the same qualitative inferences as Tables 2 and 4 . Hence, these results are omitted for brevity.

\section{Summary and discussion}

Our study investigated the relationship among strategy, the extent of IT applications for planning and control, and firm performance. Particular attention was paid to the moderating effects of impediments to IT implementation on the above relationships.

Data were obtained from a survey of CFOs of 296 publicly held Taiwanese companies, supplemented by financial data from the sample firms' publicly disclosed financial reports. The results are consistent with there being significant positive relationships between strategy and the extent of IT applications in planning and control, and between the latter and firm performance. 
Both relationships are more positive when impediments to IT implementation are low.

We adopted a holistic approach which incorporates impediments to IT implementation into strategy-IT applications-firm performance research; many prior studies focused on only part of the picture. Although the overall thrust of our results may not be surprising, several features help to increase the confidence in, as well as the richness of, our findings. First, we examined IT applications to 12 specific management functions rather than IT in general. This allowed us to discover systematic differences in IT applications across firms with different strategies. Second, we examined the moderating effects of impediments to IT implementation and specifically assessed 15 such impediments that spanned technical, human, and organizational factors. Out of this extensive list, firms indicated that the failure of software functions to meet business' demand, lack of system flexibility, lack of integration with existing systems, and lack of prior planning were most often encountered. These findings revealed similarities as well as differences in the impediments that face firms pursuing different competitive strategies.

Third, we believed that different strategies implied different organizational priorities, and therefore developed tailored sets of performance measures for each strategy type. These measures consisted of both financial and non-financial indices that spanned multiple aspects of performance. Furthermore, we provided evidence of robustness of the findings by conducting tests with both subjective and objective performance measures.

Given these results, our findings can help to sharpen understanding of the link among strategy, IT applications, and firm performance; this may include reasons for the "productivity paradox." From a practice viewpoint, they can help managers to align their firms' competitive strategies and allocate IT resources.

Our study can further benefit practice by reinforcing the importance of tailoring performance measures to the adopted strategy in evaluating IT applications, and by helping to identify the most important impediments that require attention from firms pursuing different competitive strategies.

There are, of course, some limitations to the work discussed here. Like all cross-sectional studies, our data had limited ability to identify causal linkages or to explicate the dynamics of organizational processes. Also it only focused on IT applications for planning and control. Finally, the study has been limited to Taiwanese companies. The large sample and rather favorable response rate made it likely that our findings were reflective of the situation facing Taiwanese companies in general. And to the extent that Taiwan is similar to some other countries in the region (e.g., Korea, Malaysia, and Singapore) in state of economic and IT development, the findings may be generalizable to them as well. Since some of the impediments to effective IT deployment are human and organizational variables, companies operating in different nations may not face the same mixes of impediments due to differences in their employees' work-related cultural values.

\section{Appendix A}

Survey questions for the variables in the study

A1: Types of information system software in use "Which of the following Information Technology (e.g., ERP/transaction systems) does your company currently use?" (Check one).

SAP, Oracle Financials, PeopleSoft, Lawson, J. D. Edwards, In-house/proprietary system, Other (please specify: _).

A2: IT applications for planning and control functions "Which of the following functions does your company perform with its Information Technology (e.g., ERP/transactions system)?" (yes/no).

(1) Variance analysis/management reporting.

(2) Department budgeting.

(3) Financial consolidations/reporting.

(4) Product costing/expense analysis.

(5) Measuring key performance indicators.

(6) Capital budgeting.

(7) Sales forecasting.

(8) Measuring/reporting business unit profitability.

(9) Sales performance reporting/analysis.

(10) Customer/channel profitability reporting/analysis.

(11) Manufacturing/inventory analysis.

(12) Sales/channel variance analysis.

A3: Impediments to IT implementation

"To what extent is each of the following present in your company's Information Technology implementation?" ( $1=$ "not at all," $5=$ to a very great extent.")

(1) Insufficient top management support.

(2) Employees' resistance to change.

(3) Insufficient integration with the existing systems.

(4) Insufficient people.

(5) Insufficient time.

(6) Insufficient resources (beyond people and time).

(7) Inadequate training.

(8) System cost too high.

(9) Lack of system flexibility. 
(10) Software function cannot meet business' demand.

(11) Lack of planning beforehand.

(12) Difficult to consolidate data.

(13) Lack of quality staff.

(14) Lack of specification of objectives.

(15) Lack of system stability.

A4: Strategy

"Which of the following best describes your company's strategic intent?" (check one).

(1) Build (emphasis is on increasing market share).

(2) Hold (emphasis is on preserving market share).

(3) Harvest (emphasis is on increasing short-term cashflow, often without regard to long-term effect).

(4) Divest (emphasis is on eliminating those businesses whose use of resources is inefficient and/or which are considered to be peripheral to the rest of the company).

A5: Firm performance

"Compared to your company's industry average, how does your company compare on each of the following?" (1 = "very low," 4 = "about average," 7 = "very high").

a. Long-run profitability.

b. Growth rate of revenues.

c. Employee morale, job satisfaction, and commitment.

d. Financial strength (liquidity and ability to raise financial resources).

e. Public image and goodwill.

f. Innovativeness.

g. Continuous improvement.

h. Overall performance.

\section{References}

[1] D.F. Abell, J.S. Hammond, Strategic Market Planning, Prentice Hall, Englewood Cliffs, NJ, 1979.

[2] Anonymous, Research shows high failure rate of IT projects, Journal of Accountancy 191 (2), 2001, p. 21.

[3] R.N. Anthony, J. Dearden, V. Govindarajan, Management Control Systems, Irwin, Boston, MA, 1992.

[4] E.R. Babbie, Survey Research Methods, Wadsworth, Belmont, CA, 1973.

[5] B. Balkin, G.D. Markman, L.R. Gomez-Mejia, Is CEO pay in high-technology firms related to innovation? Academy of Management Journal 43 (6), 2000, pp. 1118-1129.

[6] J. Bouwens, M.A. Abernethy, The consequences of customization on management accounting system design, Accounting, Organizations and Society 25 (3), 2000, pp. 221-241.

[7] A.C. Boynton, R.W. Zmud, Information technology planning in the 1990s: directions for practice and research, MIS Quarterly 11 (1), 1987, pp. 59-71.

[8] A. Brandyberry, A. Rai, G.P. White, Intermediate performance impacts of advanced manufacturing technology systems: an empirical investigation, Decision Sciences 30 (4), 1999, pp. 993-1020.
[9] E. Brynjolfsson, The productivity paradox of information technology, Communication of the ACM 36 (12), 1993, pp. 45-46.

[10] E. Brynjolfsson, L.M. Hitt, Beyond the productivity paradox, Communication of the ACM 41 (8), 1998, pp. 49-55.

[11] E. Brynjolfsson, L.M. Hitt, Beyond computation: information technology, organizational transformation and business performance, Journal of Economic Perspectives 14 (4), 2000, pp. 2348.

[12] J.M. Burn, C. Szeto, A comparison of the views of business and IT management on success factors for strategic alignment, Information \& Management 37 (4), 2000, pp. 197-216.

[13] T.A. Byrd, N.W. Davidson, Examining possible antecedents of IT impact on the supply chain and its effect on firm performance, Information \& Management 41 (2), 2003, pp. 243-255.

[14] K.-C. Chang, J. Jackson, V. Grover, E-commerce and corporate strategy: an executive perspective, Information \& Management 40 (7), 2003, pp. 663-675.

[15] J.M. Choe, The effect of environmental uncertainty and strategic applications of IS on a firm's performance, Information \& Management 40 (4), 2003, pp. 257-268.

[16] Comshare, The Comshare 2000 Survey of Top Financial Executives: Planning and Budgeting Today, Markham, Ontario, 2000.

[17] R.B. Cooper, R.W. Zmud, Information technology implementation research: a technological diffusion approach, Management Science 36 (2), 1990, pp. 123-133.

[18] L. Davis, B. Dehning, T. Stratopoulos, Does the market recognize IT-enabled competitive advantage? Information \& Management 40 (7), 2003, pp. 705-716.

[19] B.L. Dos Santos, L. Sussman, Improving the return on IT investment: the productivity paradox, International Journal of Information Management 20, 2000, pp. 429-440.

[20] S.W. Floyd, B. Wooldridge, Path analysis of the relationship between competitive strategy, information technology, and financial performance, Journal of Management Information Systems 7 (1), 1990, pp. 47-64.

[21] J. Galbraith, Designing Complex Organizations, Addison-Wesley, MA, 1973.

[22] L.A. Gordon, D. Miller, A contingency framework for the design of accounting information systems, Accounting, Organizations and Society 1, 1976, pp. 59-69.

[23] V. Govindarajan, A contingency approach to strategy implementation at the business-unit level: integrating administrative mechanisms with strategy, Academy of Management Journal 31 (4), 1988, pp. 828-853.

[24] V. Govindarajan, A.K. Gupta, Linking control systems to business unit strategy: impact on performance, Accounting, Organizations and Society 10 (1), 1985, pp. 51-66.

[25] V. Govindarajan, J.K. Shank, Strategic cost management: tailoring controls to strategies, Journal of Cost Management 1992, pp. $14-24$.

[26] A.K. Gupta, V. Govindarajan, Build, hold, harvest: converting strategic intentions into reality, Journal of Business Strategy 4 (3), 1984, pp. 34-47.

[27] U.G. Gupta, M. Capen, An empirical investigation of the contribution of IS to manufacturing productivity, Information \& Management 31 (4), 1996, pp. 227-233.

[28] B.D. Henderson, Perspectives on the Product Portfolio, Boston Consulting Group, Boston, MA, 1970.

[29] M.A. Hitt, R.E. Hoskisson, H. Kim, International diversification: effects on innovation and firm performance in product-diversified firms, Academy of Management Journal 40 (4), 1997, pp. $767-798$. 
[30] K.K. Hong, Y.G. Kim, The critical success factors for ERP implementation: an organizational fit perspective, Information \& Management 40 (1), 2002, pp. 25-40.

[31] C. Ittner, D. Larcker, Innovations in performance measurement: trends and research implications, Journal of Management Accounting Research 10, 1998, pp. 205-238.

[32] P.V. Jenster, Firm performance and monitoring of critical success factors in different strategic contexts, Journal of Management Information Systems 3 (3), 1986/87, pp. 17-33.

[33] J.J. Jiang, W.A. Muhanna, G. Klein, User resistance and strategies for promoting acceptance across systems types, Information \& Management 37 (1), 2000, pp. 25-36.

[34] R.S. Kaplan, D.P. Norton, The Balanced Scorecard: Translating Strategy into Action, Harvard Business School Press, Boston, MA, 1996.

[35] R.S. Kaplan, D.P. Norton, The Strategy-focused Organization, Harvard Business School Press, Boston, MA, 2001.

[36] W.R. King, R. Sabherwal, The factors affecting strategic information systems applications, Information \& Management 1992, pp. 217-235.

[37] H. Kivijarvi, T. Saarinen, Investment in information on systems and the financial performance of the firm, Information \& Management 28 (2), 1995, pp. 143-163.

[38] A.L. Lederer, A.L. Mendelow, Issues in information systems planning, Information \& Management 10 (5), 1986, pp. 245254.

[39] E.Y. Li, Perceived importance of information system success factors: a meta analysis of group differences, Information \& Management 32 (1), 1997, pp. 15-28.

[40] M. Li, L.R. Ye, Information technology and firm performance: linking with environmental, strategic and managerial contexts, Information \& Management 35 (1), 1999, pp. 43-51.

[41] M.G. Mahood, G.J. Mann, Special issue: impacts of information technology in investments on organizational performance, Journal of Management Information Systems 10 (1), 2000, pp. 97122.

[42] R.E. Miles, C.C. Snow, Organizational Strategy, Structure and Process, McGraw-Hill, New York, NY, 1978.

[43] E.P. Prien, R.E. Liske, Assessments of higher-level personnel: a comparative analysis of supervisor ratings and incumbent selfratings of job performance, Personnel Psychology 1962, pp. 187-194.

[44] P.J. Pyburn, Linking the MIS plan with corporate strategy, MIS Quarterly 1983, pp. 1-14.

[45] A. Ragowsky, N. Ahituv, S. Neumann, Identifying the value and importance of an information system application, Information \& Management 31 (2), 1996, pp. 89-102.

[46] T. Stratopulos, B. Dehning, Does successful investment in information technology solve the productivity paradox? Information \& Management 38 (2), 2000, pp. 103-117.

[47] E.J. Umble, M.M. Umble, Avoiding ERP implementation failure, Industrial Management 44, 2002, pp. 25-33.

[48] E.T.G. Wang, J.C.F. Tai, Factors affecting information systems planning effectiveness: organizational contexts and planning systems dimensions, Information \& Management 40 (4), 2003, pp. 287-303.

[49] P. Weill, The relationship between investment in information technology and firm performance: a study of the value manufacturing sector, Information Systems Research 3 (4), 1992, pp. 307-333.

[50] H.-L. Yang, Key information management issues in Taiwan and the US, Information \& Management 30 (5), 1996, pp. 251-267.

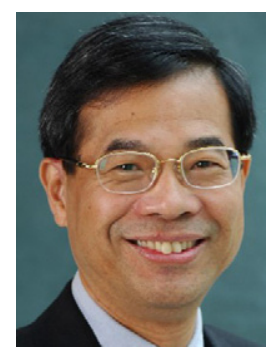

Rong-Ruey Duh is a Professor at the Department of Accounting, National Taiwan University. He holds a Ph.D. from University of Minnesota, Minneapolis. Professor Duh's teaching and research interest includes management control systems, accounting- and auditing-related judgment/decision-making, and control and assurance in e-commerce. His papers have appeared in Behavioral Research in Accounting, Advances in Quantitative Analysis of Finance and Accounting, Cuaderous Economics, and various international conferences and journals. Professor Duh has served as President of Taiwan Accounting Association.

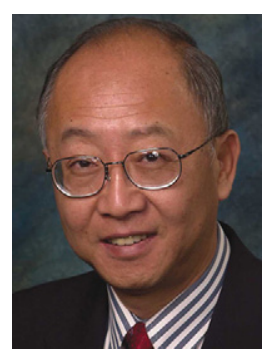

Chee W. Chow is Professor of Accounting, Emeritus, at San Diego State University. He previously taught at the University of Washington and the University of North Carolina at Chapel Hill. Professor Chow holds $\mathrm{AB}$ (with honors) and MBA degrees from Dartmouth College, an MS from the University of Rochester, and a Ph.D. from the University of Oregon. He has published well over 100 journal articles that span auditing, financial accounting, accounting education, taxation, and management accounting and controls. He has served as President of the American Accounting Association's Management Accounting Section and Editor of the Journal of Management Accounting Research.

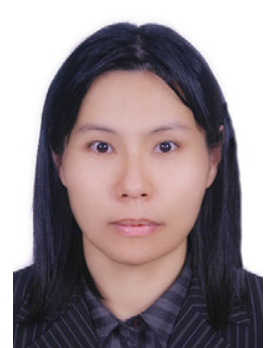

Hueiling Chen is an Assistant Professor at the Department of Finance, National Central University. She holds a Ph.D. degree from National Taiwan University. Her research interest includes financial analysts' behavior, management control systems, financial reporting, and the interface between financial and management accounting. Ms. Chen was a recipient of Vernon Zimmerman Best Paper Award. She has published papers in International Journal of Management and Decision-Making and Journal of Management (Taiwan). 